\title{
Functional characterization of DnSIZ1, a SIZ/PIAS-type SUMO E3 ligase from Dendrobium
}

\author{
Feng Liư ${ }^{\dagger}$ Xiao Wang ${ }^{\dagger}$, Mengying Su, Mengyuan Yu, Shengchun Zhang, Jianbin Lai, Chengwei Yang
} and Yaqin Wang*

\begin{abstract}
Background: SUMOylation is an important post-translational modification of eukaryotic proteins that involves the reversible conjugation of a small ubiquitin-related modifier (SUMO) polypeptide to its specific protein substrates, thereby regulating numerous complex cellular processes. The PIAS (protein inhibitor of activated signal transducers and activators of transcription [STAT]) and SIZ (scaffold attachment factor A/B/acinus/PIAS [SAP] and MIZ) proteins are SUMO E3 ligases that modulate SUMO conjugation. The characteristic features and SUMOylation mechanisms of SIZ1 protein in monocotyledon are poorly understood. Here, we examined the functions of a homolog of Arabidopsis SIZ1, a functional SIZ/PIAS-type SUMO E3 ligase from Dendrobium.
\end{abstract}

Results: In Dendrobium, the predicted DnSIZ1 protein has domains that are highly conserved among SIZ/PIAS-type proteins. DnSIZ1 is widely expressed in Dendrobium organs and has a up-regulated trend by treatment with cold, high temperature and wounding. The DnSIZ1 protein localizes to the nucleus and shows SUMO E3 ligase activity when expressed in an Escherichia coli reconstitution system. Moreover, ectopic expression of DnSIZ1 in the Arabidopsis siz1-2 mutant partially complements several phenotypes and results in enhanced levels of SUMO conjugates in plants exposed to heat shock conditions. We observed that DnSIZ1 acts as a negative regulator of flowering transition which may be via a vernalization-induced pathway. In addition, ABA-hypersensitivity of siz1-2 seed germination can be partially suppressed by DnSIZ1.

Conclusions: Our results suggest that DnSIZ1 is a functional homolog of the Arabidopsis SIZ1 with SUMO E3 ligase activity and may play an important role in the regulation of Dendrobium stress responses, flowering and development.

Keywords: Dendrobium, Flowering time regulation, Stress responses, SUMO conjugates, SUMO E3 ligase, SUMOylation

\section{Background}

In eukaryotic organisms, post-translational protein modification by methylation, phosphorylation, acetylation, glycosylation, or ubiquitination by Ub (ubiquitin) and Ubls (ubiquitin-like proteins), play important roles in diverse cellular regulatory processes $[1,2]$. Similar to ubiquitination, Ubl modifications, such as SUMOylation, are known to facilitate reversible conjugation of a SUMO (small ubiquitin-related modifier) polypeptide to protein substrates by the formation of an isopeptide bond between

\footnotetext{
* Correspondence: yqwang@scut.edu.cn

${ }^{\dagger}$ Equal contributors

Guangdong Provincial Key Laboratory of Biotechnology for Plant

Development, School of Life Sciences, South China Normal University, Guangzhou 510631, China
}

the C-terminal glycine carboxyl group of SUMO and the $\varepsilon$-amino group of the lysine residue in the conserved SUMOylation sites of substrate proteins with the consensus motif ( $\psi \mathrm{KXE} / \mathrm{D} ; \psi$, large hydrophobic residue; $\mathrm{K}$, lysine; $\mathrm{X}$, any amino acid; $\mathrm{E}$, glutamate; D, aspartate) $[1,3-5]$. SUMOylation through the SUMO conjugation pathway involves the sequential action of a series of enzymes: E1 SUMO activation enzyme, E2 SUMO conjugation enzyme and E3 SUMO ligase [3, 4, 6-9]. Subsequently, SUMO proteases can deconjugate SUMO from its associated substrate $[1,10-12]$. Ubiquitination results in the targeting of the protein substrate for proteasomal degradation [13], whereas SUMOylation is a transient and reversible process that often results in an altered function and/or cellular localization of the modified protein $[5,10]$. 
A number of studies have shown that SUMOylation is involved in a broad range of biological processes. For example, in animals and yeast, SUMO modifications affect cell cycle progression, DNA replication and repair, protein activity and stability, chromatin structural maintenance, subcellular localization and transcriptional regulation, as well as oxidative stress responses [4, 5, 10, 14-17]. SUMOylation in plants has been associated with biotic and abiotic stress responses, flowering and other aspects of development [18-24]. Moreover, protein SUMOylation by the Arabidopsis thaliana SUMO E3 ligase SIZ1 (AtSIZ1) has been shown to be involved in many environmental responses, including those related to phosphate deficiency, nitrogen assimilation, cell growth and development, tolerance of drought, cold, and high levels of copper, basal thermotolerance independent of the hormone salicylic (SA), SA-dependent signaling associated with both defense and development, flowering time regulation, and both auxin and abscisic acid (ABA) signaling [25-37]. Thus, plant post-translational modification by SUMOylation is of fundamental importance in modulating numerous signaling pathways.

SUMO E3 ligases participate in the SUMOylation pathways that are crucial to many eukaryotic biological processes. Several types of SUMO E3 ligases have been identified, including RanBP2 (RanGAP1-binding protein 2), Pc2 (Polycomb group 2), NES2/MMS21 (nonSMC element/methyl methanesulfonate sensitive 1) and SIZ/PIAS (SAP and MIZ/protein inhibitor of activated STAT) [14, 38-42]. Of these, SIZ/PIAS family proteins, which are characterized by an essential SP-RING domain, represent the largest group of SUMO E3 ligases, all of which share high degree of sequence identity. SIZ/PIAS E3 ligases have five structural motifs: an N-terminal SAP (scaffold attachment factor A/B/acinus/PIAS) motif, a PINIT (Pro-Ile-Asn-Ile-Thr) motif, a SP-RING zinc finger domain, a SXS (for serine-X-serine, where $\mathrm{X}$ is any amino acid) domain and a PHD motif (plant homeodomain) [30, 43-46]. There are two PIAS-type SUMO E3 ligases that have been identified in Arabidopsis are SIZ1 [25, 30] and MMS21/ HPY2 (NSE2/MMS21-type High Ploidy 2) [47-49].

Most studies to date of plant E3 ligases have focused on those of the experimental model $A$. thaliana and comparatively little is known about these proteins in agronomically- and horticulturally-important species. In this report, we describe the characterization of DnSIZ1 [50], a functional SUMO E3 ligase from the monocot Dendrobium, the largest genus of the Orchidaceae, which contains species that are mainly distributed in tropical and subtropical regions. The Orchidaceae are one of the largest families of flowering plants and many members of this family have high ornamental and commercial value. Here we report the activity and subcellular localization of DnSIZ1, together with an assessment of its expression patterns and function in planta through overexpression in transgenic Arabidopsis lines. Our results suggest that DnSIZ1 is a functional homolog of the Arabidopsis SIZ1 and may play an important role in the regulation of Dendrobium stress responses, flowering and development.

\section{Results}

\section{Molecular characterization of DnSIZ1}

In Arabidopsis, the PIAS-type SUMO E3 ligase AtSIZ1 regulates responses to hormones, abiotic and biotic stresses, and controls flowering [26, 27, 30, 31, 34, 37, 45]. We previously reported the isolation of $D n S I Z 1$, the Dendrobium homolog of AtSIZ1 [50]. The DnSIZ1 gene encodes protein of 864 amino acids and its nucleotide sequence was deposited in GenBank (KT375328). To investigate the biological roles of DnSIZ1, we first identified and aligned the sequences of SIZ/PIAS family proteins from the NCBI protein database. The results indicated that the DnSIZ1 deduced protein has three predicted domains (SAP, SP-RING and plant-specific PHD domains), which are conserved in AtSIZ1 [30] (Fig. 1). In addition, a Pro-Ile-Asn-Ile-Thr (PINIT) core motif was identified that is more similar to the equivalent sequence in rice (Oryza sative) [51]. But the SXP domain is different from SXS domain in Arabidopsis and rice. In plant SIZ/PIAS-type proteins there are five conserved domain structures: SAP, PHD, PINIT, SPRING and SXS [30]. The SAP domain, which is specially required for trans-repression activity of PIAS, can form a helix-extended loop-helix structure that binds to DNA [52]. The PHD domain, which is only present in plant SIZ/PIAS homologs, is a C4HC3 Zn-finger [53], while the PINIT and SP-RING domains are essential for the SUMO E3-ligase activity of SIZ/PIAS proteins [54]. Based on the protein sequence alignment and the phylogenetic relationships among DnSIZ1 and homologous proteins from other species (Figs. 1 and 2), DnSIZ1 shares high sequence identity with SIZ/PIAS proteins of other species in regard to conserved structures that are essential for SUMO E3 ligase activity and are especially similar to SIZ1 proteins in rice and sorghum.

\section{Expression patterns of DnSIZ1}

To gain insights into the potential functions of DnSIZ1, we analyzed the temporal and spatial expression patterns of its transcript accumulation using semi-quantitative RT-PCR. As shown in Fig. 3, transcripts of DnSIZ1 were detected in all organs, including roots, stems, leaves, flowers and flower buds, with the higher expression level being detected in old leaves, young leaves and young stems, and lower expression in roots and flowers. Next, we analyzed whether the expression of DnSIZ1 gene could be induced in response to abiotic and hormonal 

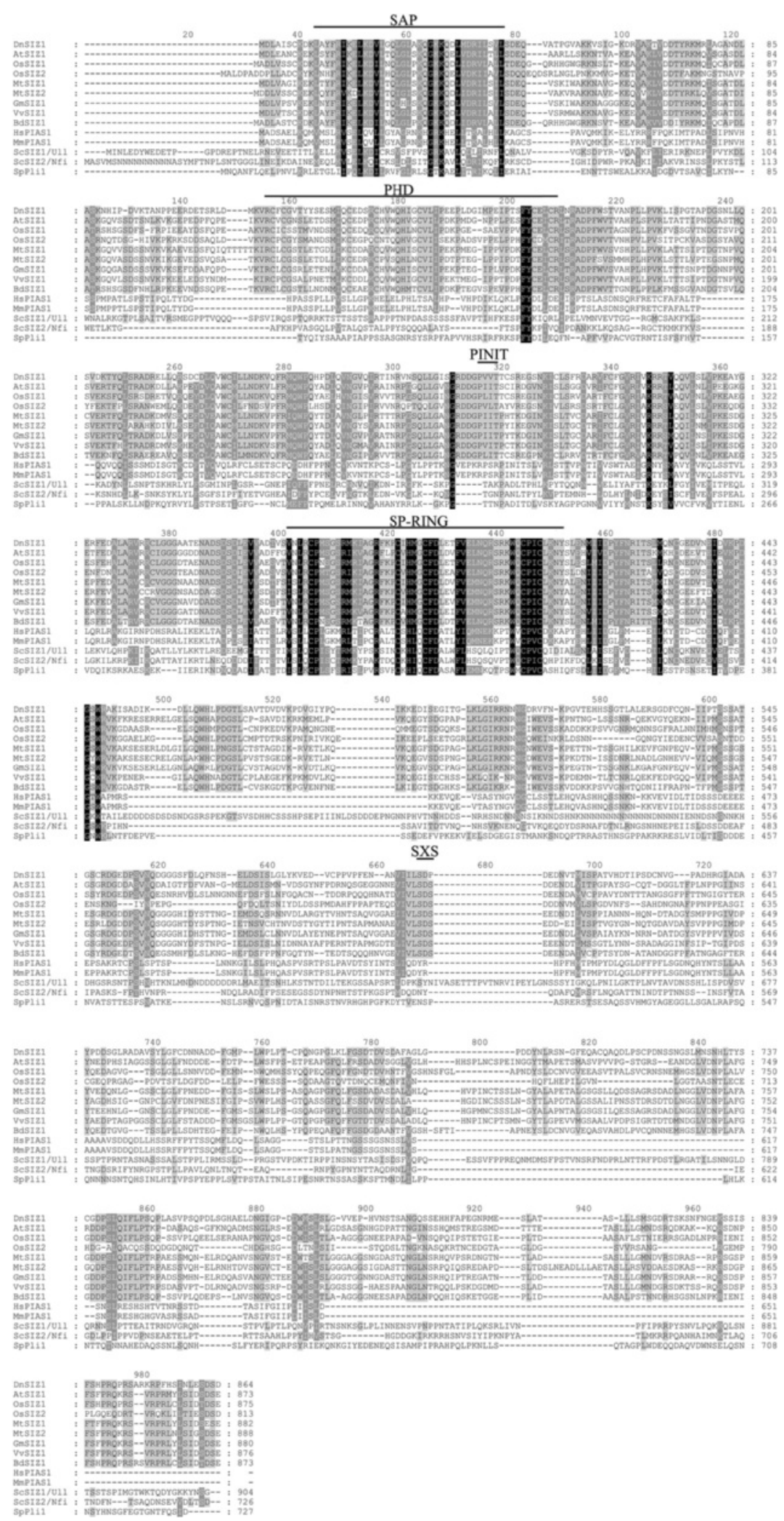

Fig. 1 (See legend on next page.) 
(See figure on previous page.)

Fig. 1 Amino acid sequence alignment of the SIZ/PIAS proteins. The deduced amino acid sequence of DnSIZ1 was aligned with the amino acid sequences of SIZ/PIAS homologs from other species. The sequences were obtained from the NCBI protein database using the BLAST network service. Amino acid sequences of SIZ/PIAS proteins from Dendrobium (Dn), Arabidopsis thaliana (At), Oryza sativa (Os), Medicago truncatula (Mt), Glycine max (Gm), Vitis vinifera (Vv), Brachypodium distachyon (Bd), Homo sapiens (Hs), Mus musculus (Mm), Saccharomyces cerevisiae (Sc) and Schizosaccharomyces pombe (Sp). The domains include: the SAP (Scaffold attachment factor A/B/acinus/PIAS); the PHD (Plant homeodomain); the PINIT (Pro-lle-Asn-Ile-Thr); the SP-RING (SIZ/PIAS-RING); and the SXS (Ser-X-Ser) domain. Black and gray shaded backgrounds indicated amino acids that were identical residues or conservative substitutions, respectively. Hyphens indicated gaps introduced to optimize alignments. Numbers above the alignment indicated the number of the amino acids from the first amino acid

stress. The results showed DnSIZ1 expression was reduced first and strongly up-regulated later when treated with high temperature $\left(45^{\circ} \mathrm{C}\right)$, cold $\left(4{ }^{\circ} \mathrm{C}\right)$ and wounding (Fig. 4).

\section{Subcellular localization of DnSIZ1}

Previous studies showed that Arabidopsis SIZ1 is localized to the nucleus and accumulates in nuclear speckles $[25,45]$. To determine the subcellular localization of the DnSIZ1 protein, we expressed the GFP fusion constructs in wild-type (Col-0) Arabidopsis roots, the line 35S::DnSIZ1:GFP \#4 was used (Fig. 5a, b). The fluorescent signal was monitored by confocal microscopy and it was determined that the fusion protein accumulated in the nucleus (Fig. 5c).

\section{Phenotypic analysis of DnSIZ1 transgenic plants}

To further understand the function of DnSIZ1, it was overexpressed in the Arabidopsis siz1-2 mutant. The siz1-2 phenotypes of dwarfism with leaf curl and short leaf length were partially functionally rescued in plants from two separate transgenic lines (HB4, HB17) (Fig. 6). For example, the length of the largest leaves of the DnSIZ1 transgenic plants was $42-54 \%$ greater than the equivalent leaves of the untransformed mutant. In addition to the stunted phenotype, siz1-2 plants are hypersensitive to exogenous ABA [33]. To test whether DnSIZ1 overexpression can functionally complement the ABA hypersensitive phenotype of siz1-2, we investigated the ABA responses of the different genotypes. We also observed that the seed germination rates of the DnSIZ1

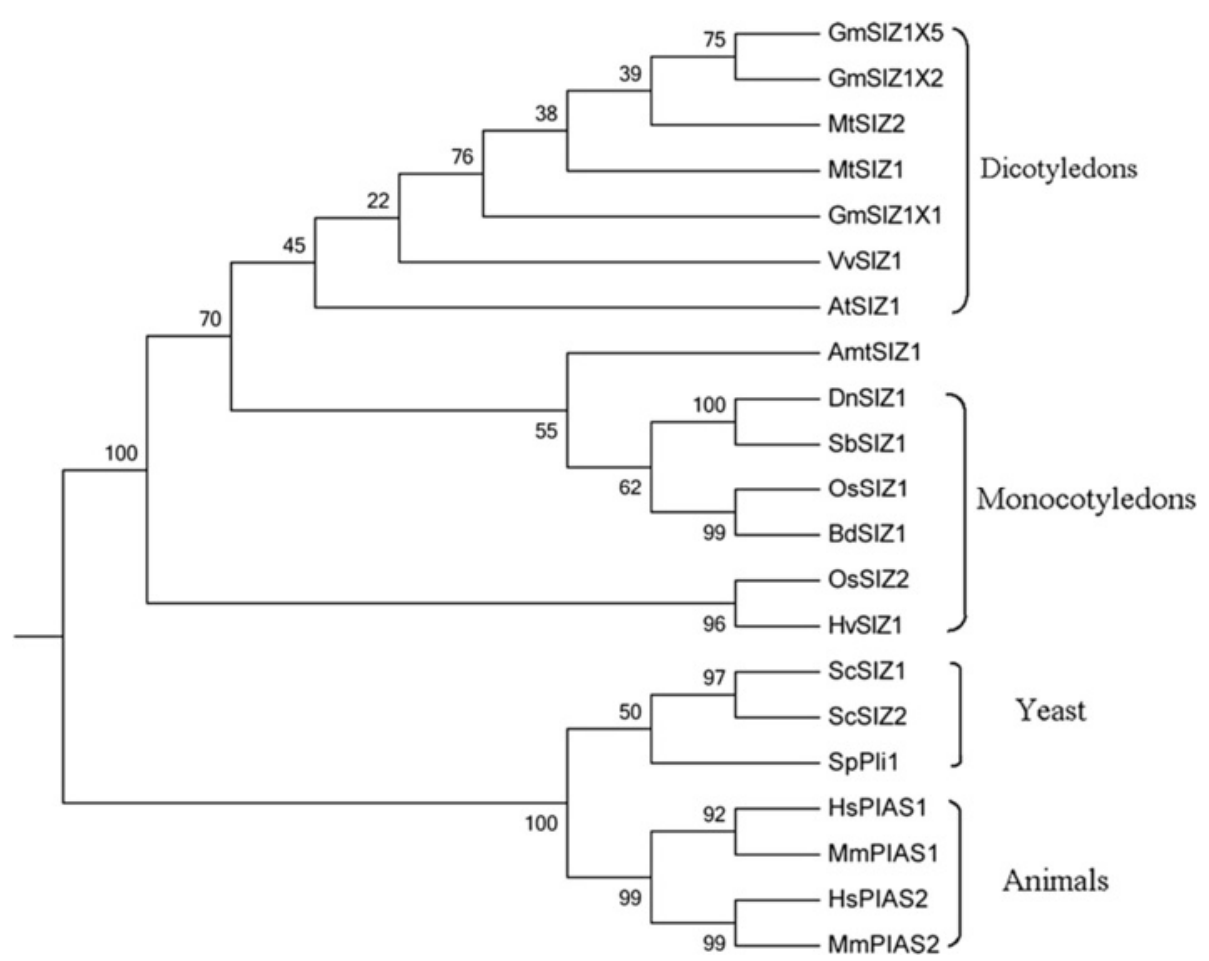

Fig. 2 Phylogenetic analysis of SIZ/PIAS proteins between Dendrobium and other species. The species are Glycine max (Gm), Medicago truncatula (Mt), Vitis vinifera (Vv), Arabidopsis thaliana (At), Amborella trichopoda (Amt), Dendrobium (Dn), Sorghum bicolor (Sb), Oryza sativa (Os), Brachypodium distachyon (Bd), Hordeum vulgare (Hv), Saccharomyces cerevisiae (Sc), Schizosaccharomyces pombe (Sp), Homo sapiens (Hs) and Mus musculus (Mm). The complete protein sequence were used to construct the phylogenetic tree with MEGA 6.06 software and the Maximum Likelihood method [83]. The numbers at the nodes indicated the bootstrap values. Bootstrap testing was performed with 1000 resamplings 


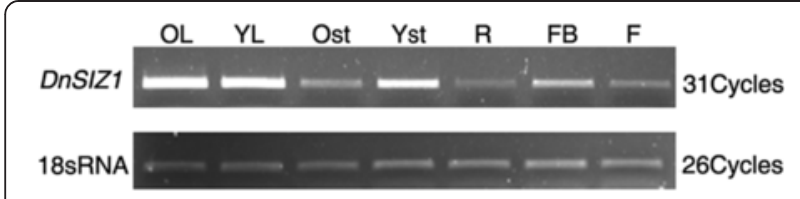

Fig. 3 The expression patterns of DnSIZ1 gene. RT-PCR analysis of DnSIZ1 transcripts in different organs of Dendrobium. 18sRNA served as an internal control. OL, old leaves; $Y L$, young leaves; Ost, old stem; Yst, young stem; R, root; FB, flower bud; F, flower

transgenic lines were strongly enhanced relative to those of siz1-2, although slightly lower than those of wild-type plants at $48 \mathrm{~h}$ after stratification (Fig. 7a, b). Furthermore, analysis of cotyledon greening showed that the DnSIZ1 transgenic lines were less sensitive to ABA than siz1-2 when grown on media containing $0.2 \mu \mathrm{M}$ ABA, although they were more sensitive than wild-type plants (Fig. 7c). Taken together, these results indicate that DnSIZ1 can partially complement at least some of the functions of AtSIZ1 in development and ABA signaling pathways.

\section{DnSIZ1 negatively regulates flowering time}

Flowering marks the transition from vegetative maturity to the reproductive stage of development [55], and the floral transition is mainly regulated by photoperiod, vernalization, the autonomous pathway and gibberellin (GA)-dependent signaling $[56,57]$. The time needed for the transition from vegetative development to reproductive growth of wild-type, siz1-2 and DnSIZ1 transgenic plants were recorded by counting the numbers of rosette leaves at the time of flowering [31]. Under normal growth conditions, rosette leaf numbers at flowering in the DnSIZ1 transgenic plants relative to siz1-2 were slightly higher, but were lower than those of wild-type and AtSIZ1 transgenic plants (Fig. 8a). However, following a vernalization treatment at $4{ }^{\circ} \mathrm{C}$ for three weeks, rosette leaf numbers at flowering of all genotypes decreased. But, rosette leaf numbers at flowering of DnSIZ1 transgenic plants are significantly more than those of siz1-2 mutant (Fig. 8b). Thus, the early flowering phenotype of siz1-2 was suppressed by overexpressing DnSIZ1 gene following vernalization, indicating that DnSIZ1 may repress flowering through vernalizationinduced transition to flowering.

\section{Heat shock-induced accumulation of SUMO conjugates in DnSIZ1 transgenic lines}

Previous studies have shown that heat shock can induce SUMOylation [58], SUMOylation in wild-type Arabidopsis and OsSIZ1/OsSIZ2 heterogenous transgenic lines are stronger than those in Arabidopsis siz1-2 plants [26, 51]. In our study, the DnSIZ1 protein also participated in response to heat shock-induced accumulation of SUMO conjugates. Under normal conditions, SUMO conjugates in wild-type, siz1-2 and DnSIZ1 overexpressing transgenic Arabidopsis plants accumulated at relatively low levels. However, when exposed to a $42{ }^{\circ} \mathrm{C}$ heat shock for $30 \mathrm{~min}$, transgenic lines produced significantly greater amounts of SUMO conjugates than Arabidopsis siz1-2 plants (Fig. 9), suggesting that DnSIZ1 can functionally complement Arabidopsis siz1-2 in the SUMO conjugation pathway. Collectively, these results suggested that the DnSIZ1 protein exhibits SUMO E3 ligase activity that can contribute to the SUMO modification pathway.

\section{DnSIZ1 is a functional SUMO E3 ligase}

In order to further demonstrate the ability of DnSIZ1 to act as a SUMO E3 ligase, we generated $p$ CDFDuet-1-FlagDnSIZ1 and $p$ CDFDuet-1-Flag-DnSIZ1 ${ }^{\text {C380A }}$ constructs, in
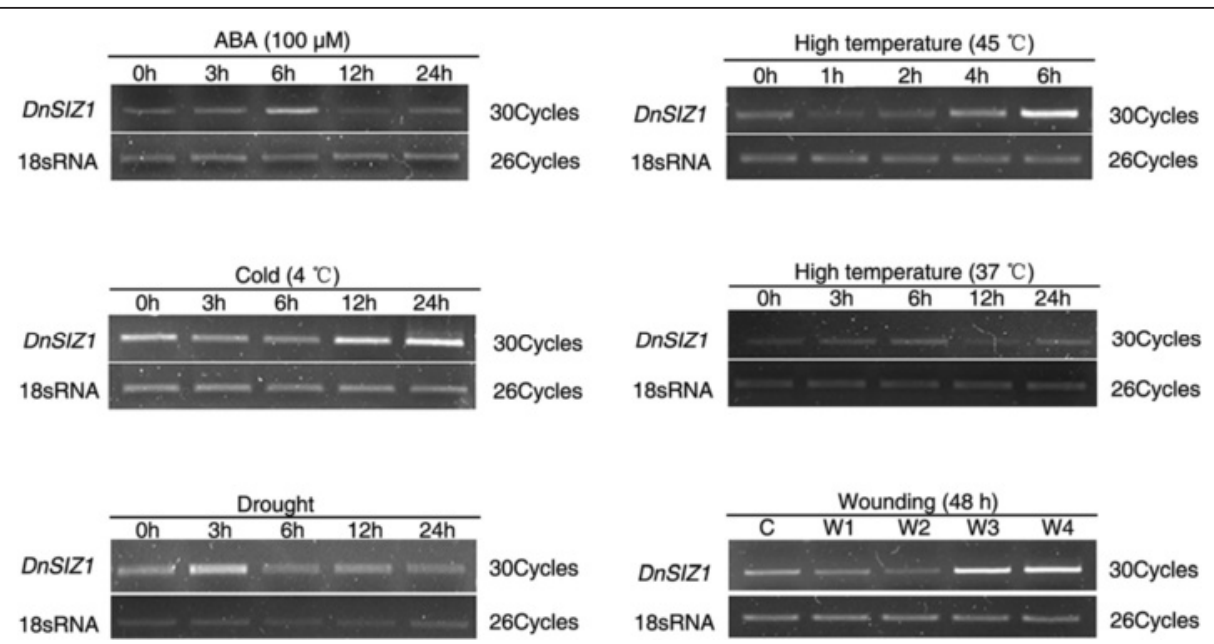

Fig. 4 Expression of DnSIZ1 in response to stress treatments. The stresses include: $A B A(100 \mu m)$, cold $\left(4{ }^{\circ} \mathrm{C}\right)$, drought, high temperature $\left(37^{\circ} \mathrm{C}\right.$, $\left.45^{\circ} \mathrm{C}\right)$, and wounding. Seedlings were collected at various time intervals after the start of the stress treatment $(\mathrm{t}=0)$. 18sRNA served as an internal control 


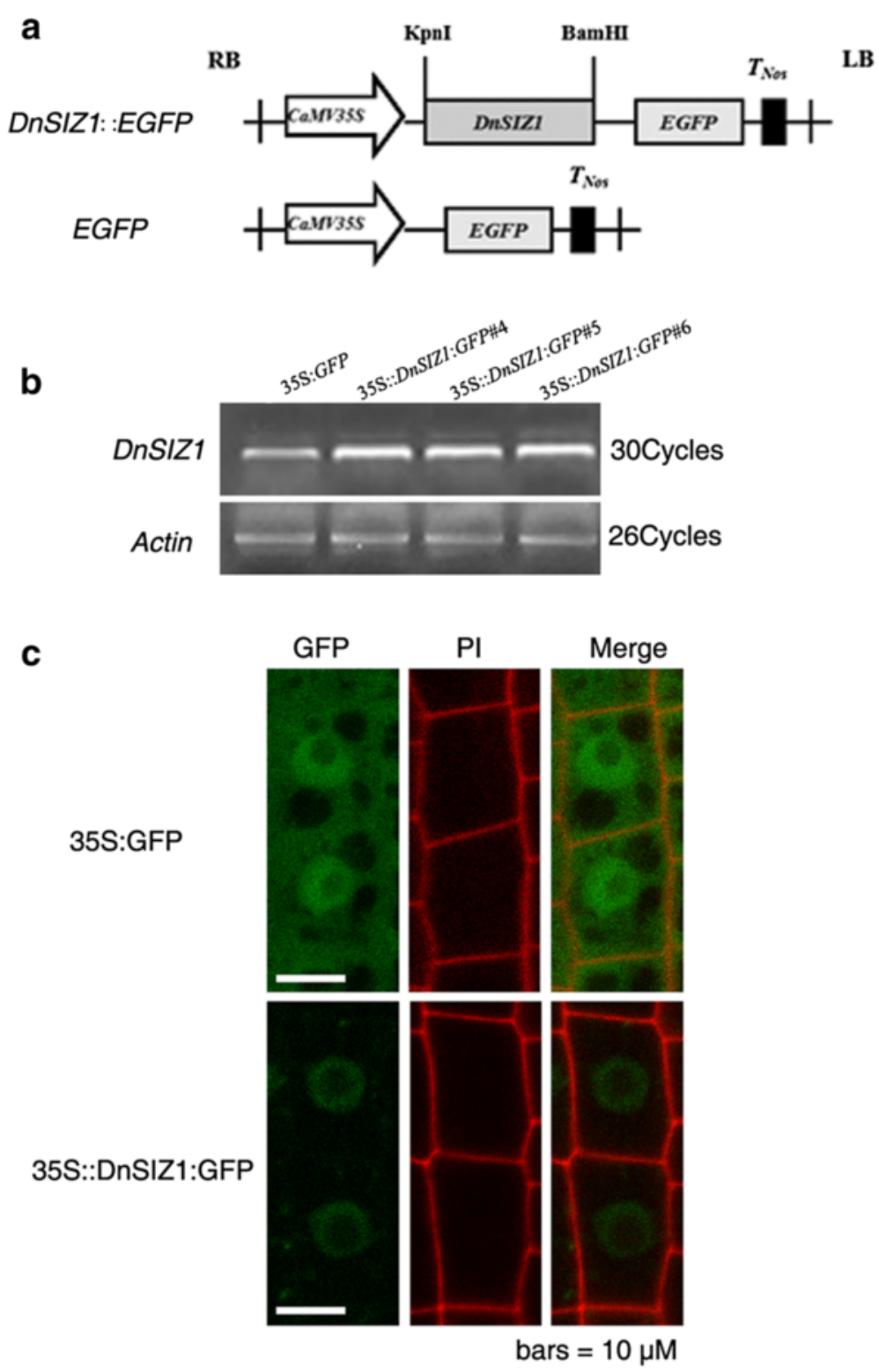

Fig. 5 Subcellular localization of DnSIZ1 protein. a Schematic representation of constructs for constitutive expression in Arabidopsis root cells. CaMV35S, cauliflower mosaic virus 35 S promoter; EGFP, green fluorescent protein; $T_{\text {Nos, }}$, nopaline synthase gene terminator are indicated. b DnSIZ1 amplification and identification of transgenic Arabidopsis lines. The plasmids were transformed into Arabidopsis wild-type using an A. tumefactionsmediated floral dip method. c Co-expression of GFP fused to DnSIZ1. 35S::DnSIZ1:GFP \#4 and 35S:GFP transgenic Arabidopsis root cells were observed, respectively. Signals were visualized using a confocal laser scanning microscopy. Panels from left to right: GFP fluorescence image; propidium iodide stained image; merged GFP fluorescence image. The GFP green color (Merged) revealed that DnSIZ1 is localized to the nucleus. Scale bars $=10 \mu \mathrm{m}$

which the C380A mutation was introduced in its SPRING, that is conserved in SIZ1s in different species and essential for SUMO ligase activity [45]. Then we performed SUMOylation assays in E.coli strain expressing DnSIZ1 together with AtSAE1a-SAE2, AtSCE1a and AtSUMO1 [59, 60]. Compared with negative control, in the presence of AtSAE1a-SAE2, AtSCE1a and AtSUMO1, SUMOylation of DnSIZ1 was detected, indicating that DnSIZ1 can be sumoylated by E2 SUMO conjugation enzyme, which is a characteristic feature of SUMO E3 ligase (Fig. 10a). In addition, the sumoylated band of DnSIZ1 ${ }^{\mathrm{C} 380 \mathrm{~A}}$ is weaker than that of DnSIZ1, which suggested the SP-RING is important for SUMOylation of DnSIZ1, providing envidence to support it is a potential SUMO E3 ligase (Fig. 10b). Coomassie brilliant blue staining of total protein was used as the loading control shown in Additional file 1: Figure S1. 

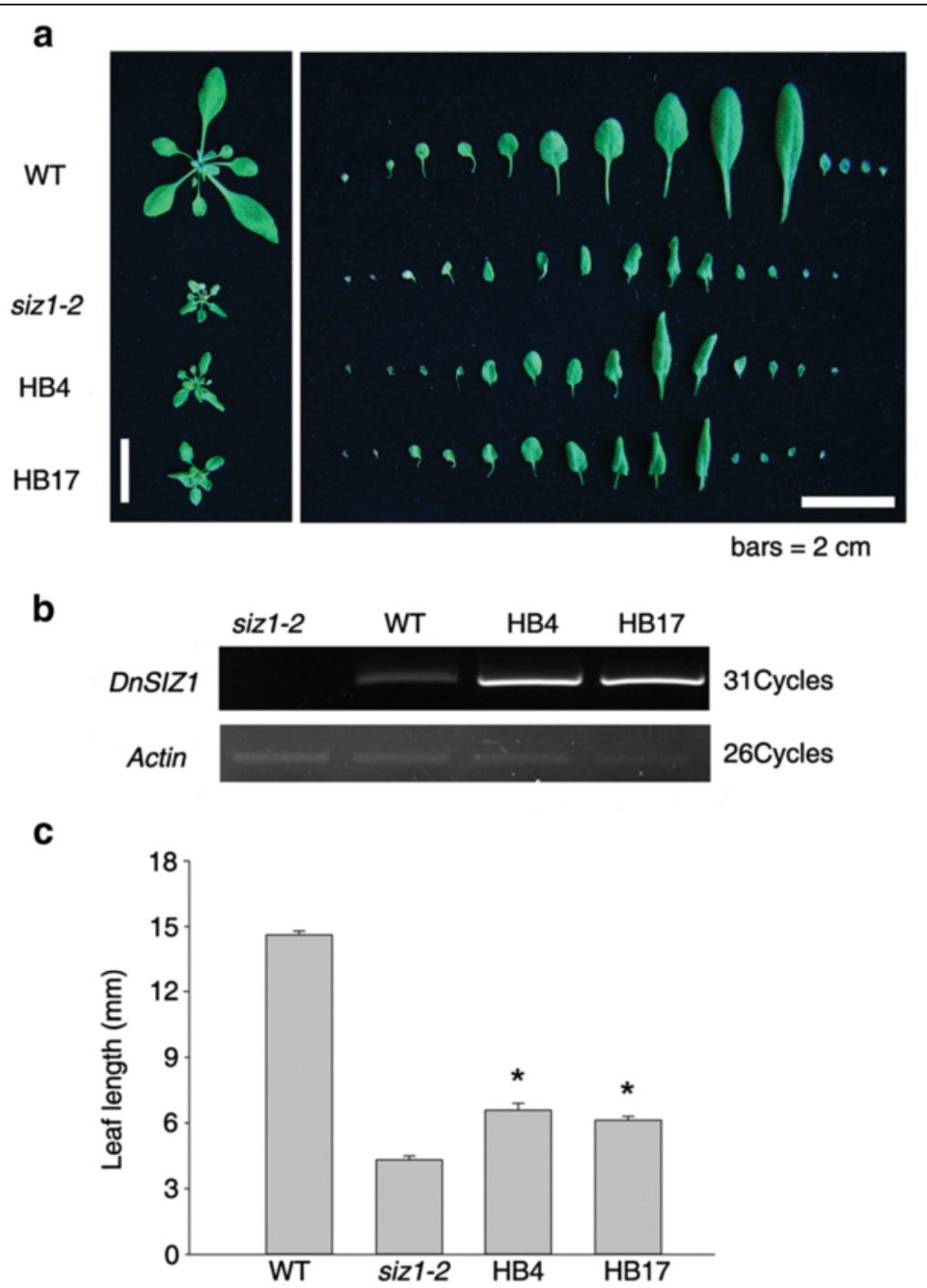

Fig. 6 Phenotypic analysis of DnSIZ1 overexpressing plants and their corresponding expression levels. a Leaf phenotypes of plants expressing DnSIZ1. The leaves were taken and arranged in each row from the left. Plants expressing DnSIZ1 in the siz1-2 (atsiz1-2) mutant were compared with Col-0 and siz1-2. b Expression of siz1-2 (atsiz1-2) plants expressing DnSIZ1. Total RNA was extracted from three-week-old plants and RT-PCR was performed using gene-specific primers (DnSIZ1-F, DnSIZ1-R). Actin was used as an internal control. c The results of statistical analysis of leaf length for each of the lines are shown in (a). The largest leaves of each line were used for leaf length measurement. The data are the means of three different experiments and indicate the percentage $( \pm$ SE) of leaf length in each transgenic plant line. Significant differences from siz $1-2$

(asterisks) at $P<0.05$ are indicated. Bar $=2 \mathrm{~cm}$

\section{Discussion}

SUMOylation is a post-translational regulatory process in eukaryotes. In plants, SUMOylation has mostly been studied in Arabidopsis, where it is involved in ABA responses, flowering time, phosphate starvation responses, salicylic acid (SA)-dependent defense responses, cold tolerance, drought, basal thermotolerance and removal of heavy metal $[25,26,31,35,37,49,61-64]$. In the context of SIZ gene functions, among the monocotyledons only SIZ1 and SIZ2 from rice have been described and it has been suggested that they functionally complement Arabidopsis AtSIZ1 in the SUMO conjugation pathway [51]. To date little is known about the biological significance and SUMOylation mechanism in the ornamental monocotyledon Dendrobium. In this current study, a Dendrobium SIZ gene, DnSIZ1, was identified based on homology to SIZ genes from rice, sorghum and Arabidopsis [50]. The SAP, SP-RING and PHD domains of DnSIZ1 have a high degree of sequence conservation with those of AtSIZ1, while the PINIT domain is most similar to that of the OsSIZ2. However, in the SXS domain, the amino acid sequence is SXP instead of SXS, which we propose represents a species specific change (Fig. 1). Given that DnSIZ1 has high degree of sequence 

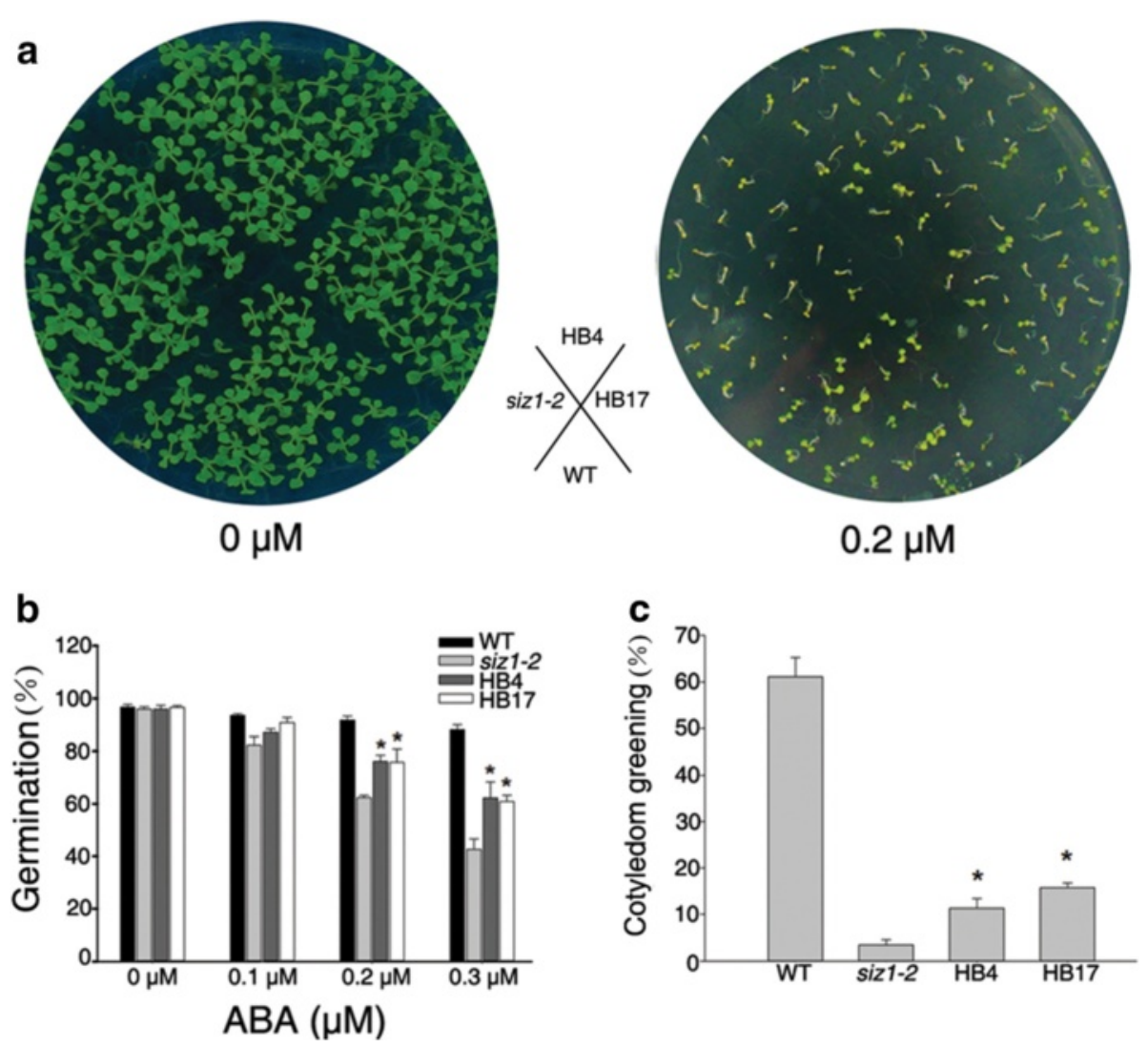

Fig. 7 Inhibition of siz1-2 ABA-hypersensitivity by overexpression of DnSIZ1. Seeds of wild-type (col-0), siz1-2 (atsiz1-2), and each of the transgenic lines (HB4, HB17) were sown on MS medium without or supplemented with ABA. a Cotyledon expansion of transgenic plants in the presence of ABA. Stratified seeds of Col-0, siz1-2 (atsiz1-2), and each of the transgenic lines (HB4, HB17) were spread in the illustrated pattern on MS medium containing 0 and $0.2 \mu \mathrm{M} \mathrm{ABA}$ and maintained under a $16 \mathrm{~h}$-light/8 h-dark conditions at $22^{\circ} \mathrm{C}$. b Germination rates of seedlings $48 \mathrm{~h}$ after stratification. c Cotyledon expansion of 5 day-old seedling in the presence or absence of $0.2 \mu \mathrm{M}$ ABA. The data represent the averages of three independent experiments. The percentages $( \pm \mathrm{SE})$ of seedlings with green cotyledon in each genotype are shown. Significant differences from atsiz1-2 (asterisks) at $P<0.05$ are indicated
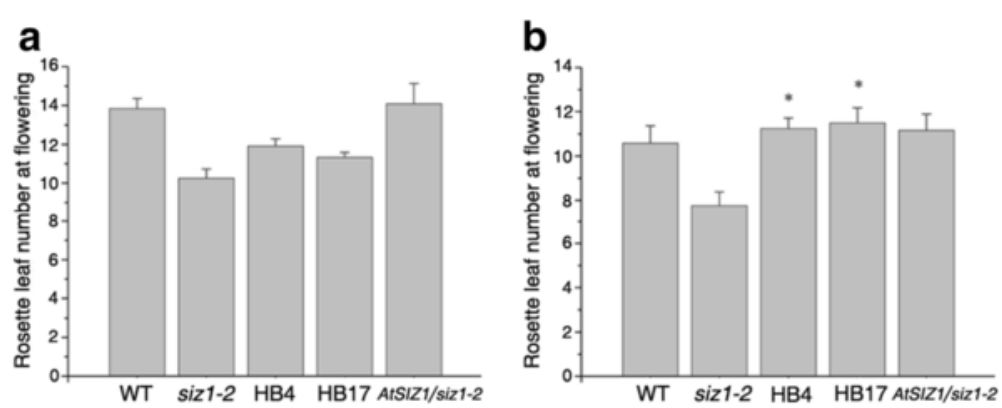

Fig. 8 Comparison of the flowering time of wild-type, siz1-2, 35S::DnSIZ1 and 35S::AtSIZ1 transgenic plants. a Seeds of the four genotypes were stratified for 2-3 d and then grown in the greenhouse under long-day conditions. $\mathbf{b}$ Seeds of the four genotypes were stratified for 3 weeks and then grown in the greenhouse under long day conditions. The flowering time was estimated based on the number of rosette leaves as described above [31]. The data are averages of three independent experiments. Values presented are the percentages of rosette leaf numbers in transgenic plant line ( \pm SE). Significant differences from atsizl-2 (asterisks) at $P<0.05$ are indicated 


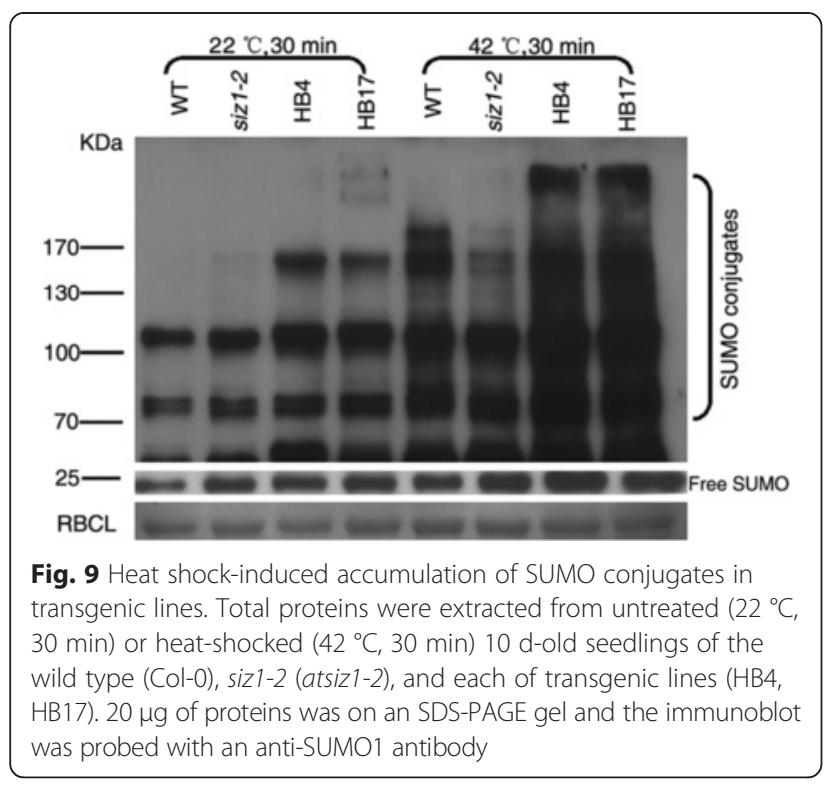

identity with SIZ1 proteins from rice and sorghum (Fig. 2) and has the canonical SP-RING domain that is necessary for the SUMO E3 ligase activity of SIZ/PIAS proteins [43], we speculate that DnSIZ1 encodes an SPRING protein with SUMO E3 ligase activity.

The expression pattern of DnSIZ1 gene was shown in Fig. 3. DnSIZ1 transcripts were detected in all tissues tested, and the expression was higher in leaves and young stems than other tissues. Evaluation of the expression in response to various environmental and hormonal stimuli (Fig. 4) showed that DnSIZ1 expression had an up-regulation trend in response to high temperature $\left(45{ }^{\circ} \mathrm{C}\right)$, cold $\left(4{ }^{\circ} \mathrm{C}\right)$ and wounding. Not only significant transcripts were induced in response to high temperature, but also SUMO conjugates increased obviously in DnSIZ1 transgenic plants after heat treatment (Fig. 9). Thus, it is likely that the activity of DnSIZ1 might be controlled at the transcriptional level and post-translational level in response to heat stress [51]. We also noted that the accumulation of SUMO conjugates in siz1-2 remained inducible by heat treatment, but the increase of SUMO conjugates in DnSIZ1 transgenic plants was highly dependent on DnSIZ1 activity, since the accumulation of SUMO conjugates was significantly lower in siz1-2 compared with DnSIZ1 transgenic plants (Fig. 9). Many reports showed that SUMOylation pathway member E3 ligase is dramatically affected by heat stress [65, 66]. Moreover, some SUMO E3 ligases such as AtSIZ1, OsSIZ1/ OSSIZ2 and HPY2 can also improve thermotolerance in plants $[26,48,51,64]$. Our results imply that DnSIZ1 plays a general role in heat stress response and may enhance heat tolerance in plants.

Although we have established that key domains of DnSIZ1 are conserved in the AtSIZ1 protein, we wanted to further confirm that DnSIZ1 can function as a SUMO E3 ligase. Accordingly, we constructed a SUMOylation reactions system in E.coli $[59,60]$ and demonstrated that DnSIZ1 is a functional SUMO E3 ligase (Fig. 10a, b). In addition, we observed the subcellular location of DnSIZ1 and the fluorescent signal in roots derived from the transgenic plants showed that DnSIZ1 protein accumulated in the nucleus (Fig. 5), which is further evidence for DnSIZ1 function as a SUMO E3 ligase in Dendrobium. It is significant because many transcription factors can be targeted by SUMO conjugation mediated by SIZ/ PIAS proteins [15, 67]. For example, the transcription factors PHR1, ICE1, ABI5, MYB30 and FLC have been identified as targets of SIZ1 in Arabidopsis. These transcription factors are involved in phosphate starvation responses, cold tolerance, ABA responses and flowering

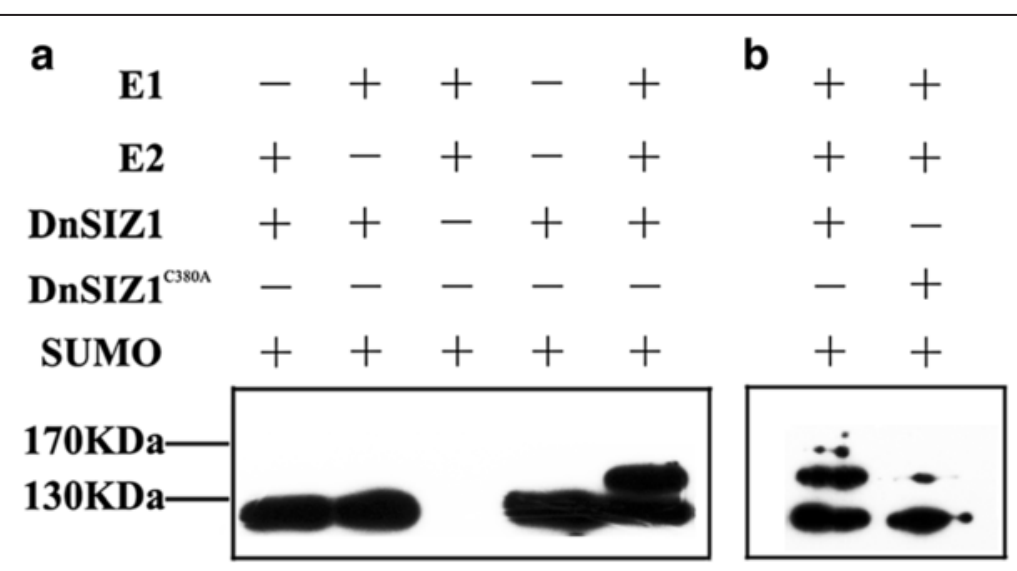

Fig. 10 In vitro assays indicate that DnSIZ1 is a functional SUMO E3 ligase. a pCDFDuet-1-Flag-DnSIZ1 was expressed in Escherichia coli and then tested for SUMOylation activity in the presence of E1 (His-AtSAE1a-AtSAE2), E2 (His-AtSCE1) and Myc-SUMO1. b pCDFDuet-1-Flag-DnSIZ1 and pCDFDuet-1-Flag-DnSIZ1 ${ }^{\text {C380A }}$ were expressed in Escherichia coli and then tested for SUMOylation activity. Immunoblots generated from these samples were probed with anti-Flag antibodies 
time $[25,29,31-33,68,69]$. Taken together, our results indicate that the DnSIZ1 protein is localized in the nucleus, may regulate transcription factors in response to a variety of environmental stresses through SIZ1-dependent SUMO conjugation.

The Orchidaceae is the largest family in the plant kingdom and Dendrobium is a sizeable genus consisting of more than a thousand species that are native to South Asia, Australia, New Zealand, and Oceania, many of which show evidence of adaptation to stresses imposed by their environments, such as nutrient starvation, heat, cold, drought and wounding [70]. While Dendrobium spp. are valued as ornamental plants worldwide, traditional breeding methods of sexual hybridization and selection are too time-consuming to meet the increasing global demand. One major obstacle for Dendrobium breeding is the prolonged vegetative phase before Dendrobium switches to reproductive development [71]. Thus, the study of flowering transition and elucidation of the underlying molecular mechanisms in Dendrobium is of great potential commercial value. Broadly speaking, five genetically defined pathways have been identified that control flowering: the vernalization pathway, the photoperiod pathway, the gibberellin-mediated pathway, the autonomous pathway and the endogenous pathway [72]. Previous studies have shown that AtSIZ1 acts as a negative regulator of the transition to flowering through mechanisms that reduce SA accumulation and involve SUMO modification of FLOWERING LOCUS D (FLD) and FLOWERING LOCUS C(FLC) [31, 69, 73]. In this current study, we found that DnSIZ1 may repress flowering through vernalization-induced floral transition (Fig. 8). Vernalization-induced flowering is an adaptation to cold conditions in many species, but most of what is known about the molecular mechanisms underlying vernalization has resulted from studies of $A$. thaliana [74]. In Dendrobium, flowering time is induced by low temperatures [75]. Moreover, DnSIZ1 expression strongly responded to cold $\left(4{ }^{\circ} \mathrm{C}\right)$ (Fig. 4). It implies the negative regulation of the flowering transition by DnSIZ1 may operate through the vernalization pathway, but the exact molecular mechanisms are still unclear because no orthologs of Arabidopsis FLC have been found in Dendrobium so far. We note that this characteristic of DnSIZ1 may have practical applications for enhancing the economic value of this ornamental crop.

The Arabidopsis siz1 mutant shows a dwarf phenotype with leaf curling and short leaves [25, 27, 28, 34] and we used these characteristics to assess functional conservation of DnSIZ1. To this end we overexpressed DnSIZ1 under the control of the CaMV35S promoter in the siz12 mutant and observed that the mutant phenotypes were indeed partially functionally complemented (Fig. 6). Moreover, DnSIZ1 overexpression partially rescued the
ABA hypersensitivity of siz1-2 in seed germination stage (Fig. 7). These results show DnSIZ1 may play an important role in plant development. Taken together, the biological functions of DnSIZ1 are multiple and complex, similar to Arabidopsis SIZ1. In order to further explore the biological functions of DnSIZ1, we are now establishing a Dendrobium transformation system to suppress DnSIZ1 expression using RNAi technology. In addition, the exact molecular mechanisms by which DnSIZ1 controls flowering time as well as the regulatory network of SUMOylation will be the target of future studies.

\section{Conclusions}

We have characterized the biological functions of DnSIZ1, a functional SIZ/PIAS-type SUMO E3 ligase in Dendrobium, and the results indicated substantial evolutionary conservation with, and a similar biological function to Arabidopsis AtSIZ1. The DnSIZ1 protein localizes to the nucleus and has SUMO E3 ligase activity when assayed in E.coli recombinant system and modulated by heat stress condition. Moreover, DnSIZ1 overexpression can partially complement several Arabidopsis siz1-2 mutant phenotypes. The expression of DnSIZ1 gene is detectable in all organs and can be induced by various stress conditions. Overall, DnSIZ1 is a functional SUMO E3 ligase and play an important role in the regulation of Dendrobium stress responses, flowering and development.

\section{Methods}

\section{Plant materials and growth conditions}

The Arabidopsis thaliana wild-type (WT) and the siz1-2 (SALK_065397) mutant [25] used in this study were the Columbia-0 (Col-0) background. Arabidopsis seeds were surface sterilized and plated on $1 \times$ Murashige and Skoog (MS) medium containing $1.5 \%$ sucrose, $0.8 \%$ agar, $\mathrm{pH} 5.7$ and then stratified for $2-3 \mathrm{~d}$ at $4{ }^{\circ} \mathrm{C}$. Seedlings grown in plates or soil were incubated in a greenhouse at $22{ }^{\circ} \mathrm{C}$ under a $16 \mathrm{~h}$-light $/ 8 \mathrm{~h}$-dark photoperiod, with a light intensity of $100 \mu \mathrm{mol} \mathrm{m}{ }^{-2} \mathrm{~s}^{-1}$ and $60-80 \%$ relative humidity. Plants of $D$. nobile were provided by the Guangdong Key Laboratory of Biotechnology for Plant Development (Guangzhou, China). The plants were grown in a greenhouse under natural light conditions. The temperature ranged from 23 to $27^{\circ} \mathrm{C}$ and the relative humidity was $70 \%$.

\section{Vector construction and plant transformation}

For preparing DnSIZ1 A. thaliana overexpression lines, the full-length DnSIZ1 cDNA was amplified from Dendrobium cDNA library by RACE and RT-PCR [50]. The cDNA was cloned into a pMD18-T vector (TaKaRa, Japan) and verified by DNA sequencing. The plasmid DNA harboring the full-length fragment of DnSIZ1 was digested with KpnI and SpeI prior to subcloning the 
DnSIZ1 fragment into the corresponding sites of the binary vector pCAMBIA1300-221, which contains that CaMV35S promoter. The constructed plasmid was transformed into the Arabidopsis siz1-2 mutant following the Agrobacterium tumefaciens-mediated floral dipping transformation method [76]. Transgenic seedlings were obtained by antibiotic selection on MS agar plates and then semi-quantitative RT-PCR analysis was used to confirm the presence of the gene. Homozygous T3 or T4 generation plants from two independent transgenic lines (HB4, HB17) were used for phenotypic analysis and subsequent experiments. To generate the 35S::DnSIZ1:GFP fusion construct, the entire coding region of DnSIZ1 was inserted directly upstream of the EGFP (enhanced green fluorescent protein) coding region in pBEGFP (pBEGFP was reconstructed based on pBin19). The constructed plasmid was transformed into the Col-0 and T2 generation plants were used for subcellular localization analysis. Primer sequences for gene amplifications are listed in Additional file 2: Table S1.

To generate the constructs expressing AtSUMO1(GG) and AtSCE1a (pACYCDuet-AtSCE1-AtSUMO1), the AtSUMO1 and AtSCE1a coding sequence fragments were separately cloned into the 2 multiple cloning sites of the expression vector pACYCDuet-1 (Novagen, Germany). The plasmid pETSAE1a2, which expresses AtSAE1a and AtSAE2, was kindly provided by Dr. Andreas Bachmair [77]. To construct the plasmid for DnSIZ1 expression, we generated the $p C D F D u e t-1-F l a g-D n S I Z 1$ and $p C D F D u e t-$ 1-Flag-DnSIZ1 ${ }^{\text {C380A }}$ constructs, the substitution of single amino acid was performed using the MutantBEST Kit (TaKaRa, Japan). The fragment was inserted into the $\mathrm{BamHI} / \mathrm{SacI}$ sites of multiple cloning site 1 of the expression vector pCDFDuet-1 (Novagen, Germany). Primer sequences for gene amplifications are listed in Additional file 2: Table S1.

\section{Analysis of expression profiles and stress treatments}

The expression of DnSIZ1 in Dendrobium vegetative and reproductive organs was investigated using semiquantitative RT-PCR. RT-PCR experiments were also employed to study the transcript levels of DnSIZ1 following plant exposure to different environment stress related treatments, including $\mathrm{ABA}$, drought, cold, and high temperature. For ABA treatments, normally cultured Dendrobium seedlings were sprayed with $100 \mu \mathrm{mol} / \mathrm{L}$ ABA (Biosharp, China) and the treated plants were harvested at $3,6,12$ and $24 \mathrm{~h}$. Control samples were collected immediately prior to the treatments. For the drought treatments, seedlings were transferred to clean and dry filter paper and the detached leaves were placed in a growth chamber and harvested at 3, 6, 12 or $24 \mathrm{~h}$ after the transfer. To investigate temperature tolerance, normally cultured Dendrobium seedlings were placed at $4{ }^{\circ} \mathrm{C}$ for the cold treatment or $37{ }^{\circ} \mathrm{C}$ for the heat shock treatment for 3 , 6,12 or $24 \mathrm{~h}$, while for the high temperature treatment seedlings were placed at $45{ }^{\circ} \mathrm{C}$ for $1,2,4$ or $6 \mathrm{~h}$. The wounding treatment involved slicing off the $1 \mathrm{~cm}$ leaf apex with a sterile razor blade: the area $1 \mathrm{~cm}$ from the excised site was defined as W1 and regions at sequential $1 \mathrm{~cm}$ intervals adjacent to W1 were defined as W2, W3, and W4, respectively. The wound-treated plants were placed in the growth chamber, and leaf samples were collected after $48 \mathrm{~h}$ [78]. After all treatments, plant materials were immediately frozen in liquid $\mathrm{N}_{2}$ and stored at $-80{ }^{\circ} \mathrm{C}$ until needed for RNA extraction. Total RNA samples were extracted and processed for semi-quantitative RT-PCR as described before [79]. Primer sequences for gene amplifications are listed in Additional file 2: Table S1. Each treatment was repeated with three biological replicates.

\section{RNA isolation and semi-quantitative RT-PCR}

Total RNA was extracted from the roots, stems, leaves, flowers and flower buds of Dendrobium seedlings as described previously [80]. Arabidopsis total RNA was isolated from seedlings using TRIZOL reagent (Invitrogen, USA) according to the manufacturer's instructions and then treated with DNase I (deoxyribonuclease I, Sigma, USA) at room temperature for $15 \mathrm{~min}$ and at $70{ }^{\circ} \mathrm{C}$ for $10 \mathrm{~min}$.

For RT-PCR analyses, $2 \mu \mathrm{g}$ sample of total RNA was used as a template for the first strand cDNA synthesis with M-MLV reverse transcriptase and an Oligo $(\mathrm{dT})_{18}$ primer (TaKaRa, Japan). Specific gene expression levels were analyzed by semi-quantitative RT-PCR [79].

Primer pairs were designed using Primer Premier 5.0 (Premier, Canada). Primer sequences for gene amplifications are listed in Additional file 2: Table S1. Each PCR assay was repeated with three biological replicates, each of which had three technical replicates, giving nine measurements for each treatment/time point.

\section{Subcellular localization assay}

The constructs encoding DnSIZ1:GFP or GFP alone were introduced separately into Arabidopsis wide-type by transformation, and T2 plants were used for subcellular localization analysis. Seedlings of 35S:GFP and 35S::DnSIZ1:GFP \#4 were grown vertically on MS agar plates. Roots of 7 day-old transgenic seedlings were stained with $10 \mu \mathrm{g} / \mathrm{mL}$ propidium iodide (PI, Sigma, USA) solution for $1 \mathrm{~min}$, washed with sterilized water, placed on microscope slides in a drop of water and then imaged using confocal microscopy. Fluorescence analysis was performed using a Carl Zeiss LSM710 confocal laser microscope (LSM710, Carl Zeiss, Germany). 


\section{$A B A$ germination and flowering time assays}

To investigate ABA sensitivity, plants of the different genotypes were grown in the same conditions and seeds were collected at the same time. For each comparison, seeds from WT, siz1-2 and two transgenic lines (HB4, HB17) were planted in triplicate on plates containing MS medium with or without different concentrations of ABA $(0.1,0.2$ and $0.5 \mu \mathrm{M})$. The plates were incubated at $4{ }^{\circ} \mathrm{C}$ for 3 days before being transferred to $22{ }^{\circ} \mathrm{C}$ under long day conditions. The percentage of seed germination was scored at indicated times, with germination defined as an obvious emergence of the radicle through the seed coat. Cotyledon greening was quantified at the time of cotyledon opening and epicotyl exposure as the percentage of seedlings with green cotyledons. The plates were scanned using an Epson perfection V200 photo scanner (Epson, Japan). Flowering time analysis was performed by counting the numbers of rosette leaves at the time of flowering, at least 15-20 plants were used to determine the flowering time of each genotype [31], vernalization treatment was at $4{ }^{\circ} \mathrm{C}$ for three weeks.

\section{In vivo analysis of SUMO conjugates}

For the analysis of SUMO conjugates, 10 day-old seedlings grown on medium were shocked at a $42{ }^{\circ} \mathrm{C}$ heat stress for $30 \mathrm{~min}$ and the untreated seedlings were as a control. Plant tissues $(0.1 \mathrm{~g})$ were ground in grinding buffer $(0.5 \mathrm{ml})$ (50 mM sodium phosphate $\mathrm{pH} 7.0$, $200 \mathrm{mM} \mathrm{NaCl}, 10 \mathrm{mM} \mathrm{MgCl} 2$ and $10 \%$ glycerol, one protease inhibitor cocktail tablet/10 ml), vibrated and placed for $10 \mathrm{~min}$ on ice, then centrifuged at the maximum speed at $4{ }^{\circ} \mathrm{C}$ for $10 \mathrm{~min}$ and kept the supernatant. Protein concentration was measured using the Bio-Rad Protein Assay reagent (Bio-Rad, USA), and proteins were separated by sodium dodecyl sulphate-polyacrylamide gel electrophoresis (SDS-PAGE), transferred to polyvinylidene difluoride membrane (Millipore, USA), probed with anti-SUMO1 polyclonal antibody (Abcam, UK) and goat anti-rabbit IgG (Sigma, USA), and detected with the ECL plus Western Blotting Detection system (KeyGEN, China) following the manufacturer's instructions.

\section{In vitro SUMOylation assays}

To reconstitute the SUMOylation system in vitro, pETSAE1a2 was co-transformed with pACYCDuet-AtSCE1AtSUMO1 or pACYCDuet-AtSUMO1 into Escherichia coli BL21 (DE3) cells to generate competent cells [59, 60]. For the SUMOylation reaction, the $p C D F D u e t-1-F l a g-$ DnSIZ1 and $p$ CDFDuet-1-Flag-DnSIZ1 ${ }^{\text {C380A }}$ constructs were transformed into the above competent cells, respectively. Transformants were cultured in $5 \mathrm{ml}$ of LuriaBertani (LB) medium and shaken at $37^{\circ} \mathrm{C}$ until the culture $\mathrm{OD}_{600}$ was 0.4-0.6, followed by the addition of $0.5 \mathrm{mM}$ isopropyl $\beta$-D-thiogalactopyranoside (IPTG). After an approximately $12 \mathrm{~h}$ induction at $25{ }^{\circ} \mathrm{C}$, cells were harvested from $300 \mu \mathrm{l}$ of cell culture and $100 \mu \mathrm{l}$ of $1 \times$ SDS-PAGE sample buffer was added, followed by denaturation at $100{ }^{\circ} \mathrm{C}$ for 3 mins. Equal amounts of protein extracts were loaded onto each lane of an SDS-polyacrylamide gel. Electrophoresed proteins were blotted onto polyvinylidene fluoride (PVDF) membranes (Millipore, USA), and incubated with anti-FLAG antibody (Rabbit) (Sigma, USA) and sequentially with goat anti-rabbit IgG (Sigma, USA). Immunoblots were visualized by chemiluminescence (Millipore, USA).

\section{Sequences and bioinformatics analysis}

Except for DnSIZ1, all of the protein sequences of the SIZ1 homologs identified by BlastP were downloaded from National Center for Biotechnology Information (NCBI) (http://www.ncbi.nlm.nih.gov/). Sequences of plantspecific SIZ proteins were then aligned using Clustal $X 2$ [81]. A phylogenetic tree was constructed with the Maximum likelihood method [82], as described in MEGA 6.06 [83].

\section{Statistical analyses}

Statistical analyses were performed using Microsoft Excel software (Microsoft Corp, USA) and a one-way analysis of variance (ANOVA). When significance was detected, sample means were separated using an LSD test at the $P<0.05$ level of significance with SPSS statistical software (SPSS, USA). The leaf length was measured using DIGIMIZER 3.2.1.0 (http://www.digimizer.com/).

\section{Additional files}

Additional file 1: Figure S1. Coomassie brilliant blue staining of total protein. Lanes 1, 3, 5, 7, 9 and 11, protein extracts before IPTG induction; lanes 2, 4, 6, 8, 10 and 12, protein extracts after IPTG induction. (TIFF $300 \mathrm{~kb}$ )

Additional file 2: Table S1. Primers used in this study. (PDF $88 \mathrm{~kb}$ )

\section{Abbreviations}

CaMV: Cauliflower mosaic virus; FLC: FLOWERING LOCUS C; FLD: FLOWERING LOCUS D; GA: gibberellin; GFP: green fluorescent protein; IPTG: isopropyl $\beta$ D-thiogalactopyranoside; LB: Luria-Bertani; MMS21: methyl methanesulfonate sensitive 1; MS: Murashige and Skoog; PIAS: protein inhibitor of activated STAT; RNAi: RNA interference; RT-PCR: reverse transcription-PCR; SA: salicylic acid; SAP: scaffold attachment factor A/B/acinus/PIAS; SIZ1: SAP and MIZ domain protein; STAT: signal transducers and activators of transcription; SUMO: small ubiquitin-related modifier; Ub: ubiquitin; Ubls: ubiquitin-like proteins; WT: wild type.

Competing interests

The authors declare that they have no competing interests.

\section{Authors' contributions}

FL and XW carried out the experiments, analyzed the data and drafted the manuscript. MYY constructed the SUMOylation detecting system. MYS performed data analysis. SCZ, JBL and CWY participated in experiment design and manuscript revision. YQW conceived of the study, participated in its design and revised the manuscript. All authors read and approved the final manuscript. 


\section{Authors' information}

Not applicable.

\section{Availability of supporting data}

The DnSIZ1 sequence data were deposited in GenBank

(http://www.ncbi.nlm.nih.gov) under the accession of KT375328. Other supporting data, Additional file 1.pdf and Additional file 2.pdf, are included as additional files of this manuscript.

\section{Acknowledgements}

We acknowledge Dr. Andreas Bachmair for E1 plasmid, Dr. Jing Bo Jin for AtSIZ1/siz1-2 transgenic seeds, Dr. Qingsheng Ye and Shan Liang for Dendrobium plants, Dr. Yiyang Liu and Jieming Jiang for contributions in the construction of SUMOylation system, We also thank PlantScribe (www.plantscribe.com) for manuscript editing. The authors greatly acknowledge Guangdong Provincial Key Laboratory of Biotechnology for Plant Development for providing the research facilities. This work was supported by Natural Science Foundation of Guangdong Province (S2013010013463, S2011010003358), Science and Technology Plan Project of Guangdong Province (2013B020201003, 2011A00201004) and National Natural Science Foundation of China (31171994).

\section{Funding}

This work was supported by Natural Science Foundation of Guangdong Province (S2013010013463, S2011010003358), Science and Technology Plan Project of Guangdong Province (2013B020201003, 2011A00201004) and National Natural Science Foundation of China (31171994).

\section{Received: 23 January 2015 Accepted: 11 September 2015} Published online: 17 September 2015

\section{References}

1. Kerscher $\mathrm{O}$, Felberbaum $\mathrm{R}$, Hochstrasser M. Modification of proteins by ubiquitin and ubiquitin-like proteins. Annu Rev Cell Dev Biol. 2006;22:159-80.

2. Vertegaal AC. Uncovering ubiquitin and ubiquitin-like signaling networks. Chem Rev. 2011;111:7923-40.

3. Schmidt D, Müller S. PIAS/SUMO: new partners in transcriptional regulation Cell Mol Life Sci. 2003;60:2561-74.

4. Johnson ES. Protein modification by SUMO. Annu Rev Biochem. 2004;73:355-82.

5. Geiss-Friedlander R, Melchior F. Concepts in sumoylation: a decade on Nat Rev Mol Cell Bio. 2007;8:947-56.

6. Seeler J, Dejean A. Nuclear and unclear functions of SUMO. Nat Rev Mol Cell Bio. 2003;4:690-9.

7. Rytinki MM, Kaikkonen S, Pehkonen P, Jääskeläinen T, Palvimo JJ. PIAS proteins: pleiotropic interactors associated with SUMO. Cell Mol Life Sci. 2009:66:3029-41.

8. Wilkinson K, Henley J. Mechanisms, regulation and consequences of protein SUMOylation. Biochem J. 2010:428:133-45.

9. Cubeñas-Potts C, Matunis MJ. SUMO: a multifaceted modifier of chromatin structure and function. Dev Cell. 2013;24:1-12.

10. Hay RT. SUMO: a history of modification. Mol Cell. 2005;18:1-12.

11. Meulmeester E, Melchior F. Cell biology: SUMO. Nature. 2008;452:709-11.

12. Hickey CM, Wilson NR, Hochstrasser M. Function and regulation of SUMO proteases. Nat Rev Mol Cell Bio. 2012;13:755-66.

13. Konstantinova IM, Tsimokha AS, Mittenberg AG. Role of proteasomes in cellular regulation. Int Rev Cell Mol Biol. 2008;267:59-124.

14. Verger A, Perdomo J, Crossley M. Modification with SUMO. Embo Rep. 2003:4:137-42

15. Gill G. Something about SUMO inhibits transcription. Curr Opin Genet Dev. 2005;15:536-41.

16. Park S, Chae M, Kim B, Seo T, Jang I, Choi J, et al. SUMOylated IRF-1 shows oncogenic potential by mimicking IRF-2. Biochem Bioph Res Co. 2010:391:926-30.

17. Feligioni M, Nisticò R. SUMO: a (Oxidative) stressed protein. Neuromol Med. 2013:15:707-19.

18. Novatchkova M, Budhiraja R, Coupland G, Eisenhaber F, Bachmair A. SUMO conjugation in plants. Planta. 2004;220:1-8.

19. Downes $B$, Vierstra RD. Post-translational regulation in plants employing a diverse set of polypeptide tags. Biochem Soc T. 2005;33:393-400.

20. Chosed R, Mukherjee S, Lois L, Orth K. Evolution of a signalling system that incorporates both redundancy and diversity: Arabidopsis SUMOylation. Biochem J. 2006:398:521-9.
21. Castro PH, Tavares RM, Bejarano ER, Azevedo H. SUMO, a heavyweight player in plant abiotic stress responses. Cell Mol Life Sci. 2012;69:3269-83.

22. Park HJ, Yun D. New insights into the role of the small ubiquitin-like modifier (SUMO) in plants. Int Rev Cell Mol Biol. 2012;300:161-209.

23. Du Toit A. SUMOylation mediates brassinosteroid effects. Nat Rev Mol Cell Bio. 2014;15:632

24. Park HJ, Kim W, Park HC, Lee SY, Bohnert HJ, Yun D. SUMO and SUMOylation in plants. Mol Cells. 2011;32:305-16.

25. Miura K, Rus A, Sharkhuu A, Yokoi S, Karthikeyan AS, Raghothama KG, et al. The Arabidopsis SUMO E3 ligase SIZ1 controls phosphate deficiency responses. Proc Natl Acad Sci U S A. 2005;102:7760-5.

26. Yoo CY, Miura K, Jin JB, Lee J, Park HC, Salt DE, et al. SIZ1 small ubiquitin-like modifier E3 ligase facilitates basal thermotolerance in Arabidopsis independent of salicylic acid. Plant Physiol. 2006;142:1548-58.

27. Catala R, Ouyang J, Abreu IA, Hu Y, Seo H, Zhang X, et al. The Arabidopsis E3 SUMO ligase SIZ1 regulates plant growth and drought responses. Plant Cell. 2007;19:2952-66.

28. Lee J, Nam J, Park HC, Na G, Miura K, Jin JB, et al. Salicylic acid-mediated innate immunity in Arabidopsis is regulated by SIZ1 SUMO E3 ligase. Plant J. 2007:49:79-90.

29. Miura K, Jin JB, Lee J, Yoo CY, Stirm V, Miura T, et al. SIZ1-mediated sumoylation of ICE1 controls CBF3/DREB1A expression and freezing tolerance in Arabidopsis. Plant Cell. 2007:19:1403-14.

30. Miura K, Jin JB, Hasegawa PM. Sumoylation, a post-translational regulatory process in plants. Curr Opin Plant Biol. 2007;10:495-502.

31. Jin JB, Jin YH, Lee J, Miura K, Yoo CY, Kim WY, et al. The SUMO E3 ligase, AtSIZ1, regulates flowering by controlling a salicylic acid-mediated floral promotion pathway and through affects on FLC chromatin structure. Plant J. 2008:53:530-40.

32. Miura K, Hasegawa PM. Regulation of cold signaling by sumoylation of ICE1. Plant Signal Behav. 2008;3:52-3

33. Miura $K$, Lee J, Jin JB, Yoo CY, Miura T, Hasegawa PM. Sumoylation of ABI5 by the Arabidopsis SUMO E3 ligase SIZ1 negatively regulates abscisic acid signaling. Proc Natl Acad Sci U S A. 2009;106:5418-23.

34. Miura K, Lee J, Miura T, Hasegawa PM. SIZ1 controls cell growth and plant development in Arabidopsis through salicylic acid. Plant Cell Physiol. 2010;51:103-13.

35. Chen CC, Chen YY, Tang IC, Liang HM, Lai CC, Chiou JM, et al. Arabidopsis SUMO E3 ligase SIZ1 is involved in excess copper tolerance. Plant Physiol. 2011;156:2225-34.

36. Park BS, Song JT, Seo HS. Arabidopsis nitrate reductase activity is stimulated by the E3 SUMO ligase AtSIZ1. Nat Commun. 2011;2:400.

37. Miura K, Okamoto H, Okuma E, Shiba H, Kamada H, Hasegawa PM, et al. SIZ1 deficiency causes reduced stomatal aperture and enhanced drought tolerance via controlling salicylic acid-induced accumulation of reactive oxygen species in Arabidopsis. Plant J. 2013;73:91-104.

38. Johnson ES, Gupta AA. An E3-like factor that promotes SUMO conjugation to the yeast septins. Cell. 2001;106:735-44.

39. Kahyo T, Nishida T, Yasuda H. Involvement of PIAS1 in the Sumoylation of tumor suppressor p53. Mol Cell. 2001;8:713-8.

40. Rose A, Meier I. A domain unique to plant RanGAP is responsible for its targeting to the plant nuclear rim. Proc Natl Acad Sci U S A. 2001;98:15377-82.

41. Pichler A, Gast A, Seeler JS, Dejean A, Melchior F. The nucleoporin RanBP2 has SUMO1 E3 ligase activity. Cell. 2002;108:109-20.

42. Kagey MH, Melhuish TA, Wotton D. The polycomb protein PC2 is a SUMO E3. Cell. 2003:113:127-37.

43. Sharrocks AD. PIAS proteins and transcriptional regulation-more than just SUMO E3 ligases? Gene Dev. 2006;20:754-8.

44. Garcia-Dominguez M, March-Diaz R, Reyes JC. The PHD domain of plant PIAS proteins mediates Sumoylation of bromodomain GTE proteins. J Biol Chem. 2008:283:21469-77.

45. Cheong MS, Park HC, Hong MJ, Lee J, Choi W, Jin JB, et al. Specific domain structures control abscisic acid-, salicylic acid-, and stress-mediated SIZ1 phenotypes. Plant Physiol. 2009;151:1930-42.

46. Cheong MS, Park HC, Bohnert HJ, Bressan RA, Yun D. Structural and functional studies of SIZ1, a PIAS-type SUMO E3 ligase from Arabidopsis. Plant Signal Behav. 2010;5:567-9.

47. Huang L, Yang S, Zhang S, Liu M, Lai J, Qi Y, et al. The Arabidopsis SUMO E3 ligase AtMMS21, a homologue of NSE2/MMS21, regulates cell proliferation in the root. Plant J. 2009;60:666-78. 
48. Ishida T, Fujiwara S, Miura K, Stacey N, Yoshimura M, Schneider K, et al. SUMO E3 ligase HIGH PLOIDY2 regulates endocycle onset and meristem maintenance in Arabidopsis. Plant Cell. 2009;21:2284-97.

49. Ishida T, Yoshimura M, Miura K, Sugimoto K. MMS21/HPY2 and SIZ1, two Arabidopsis SUMO E3 ligases, have distinct functions in development. PLoS One. 2012;7, e46897.

50. Wang Y, Zhong K, Yang C, Liang S. Cloning and sequence analysis of SIZ1 gene in Dendrobium. Journal of South China Normal University (Natural Science Edition). 2011;0:28.

51. Park HC, Kim H, Koo SC, Park HJ, Cheong MS, Hong H, et al. Functional characterization of the SIZ/PIAS-type SUMO E3 ligases, OsSIZ1 and OsSIZ2 in rice. Plant Cell Environ. 2010;33:1923-34.

52. Aravind $\mathrm{L}$, Koonin EV. SAP-a putative DNA-binding motif involved in chromosomal organization. Trends Biochem Sci. 2000;25:112-4.

53. Bienz. The PHD finger, a nuclear protein-interaction domain. Trends Biochem Sci. 2006:31:35-40.

54. Takahashi Y. Yeast PIAS-type UII1/Siz1 is composed of SUMO ligase and regulatory domains. J Biol Chem. 2005;280:35822-8.

55. Bäurle I, Dean C. The timing of developmental transitions in plants. Cell. 2006;125:655-64.

56. Michaels SD, Amasino RM. LOSS of FLOWERING LOCUS C activity eliminates the late-flowering phenotype of FRIGIDA and autonomous pathway mutations but not responsiveness to vernalization. Plant Cell. 2001;13:935-41.

57. He Y, Amasino RM. Role of chromatin modification in flowering-time control. Trends Plant Sci. 2005:10:30-5.

58. Kurepa J, Walker JM, Smalle J, Gosink MM, Davis SJ, Durham TL, et al. The small ubiquitin-like modifier (SUMO) protein modification system in Arabidopsis accumulation of sumo1 and -2 conjugates is increased by stress. J Biol Chem. 2003;278:6862-72.

59. Okada S, Nagabuchi M, Takamura Y, Nakagawa T, Shinmyozu K, Nakayama J, et al. Reconstitution of Arabidopsis thaliana SUMO pathways in E. coli: functional evaluation of SUMO machinery proteins and mapping of SUMOylation sites by mass spectrometry. Plant Cell Physiol. 2009;50:1049-61.

60. Wu J, Kim S, Kwak MS, Jeong JB, Min HJ, Yoon HG, et al. High mobility group nucleosomal binding domain 2 (HMGN2) SUMOylation by the SUMO E3 ligase PIAS1 decreases the binding affinity to nucleosome core particles. J Biol Chem. 2014;289:20000-11.

61. Lois LM, Lima CD, Chua N. Small ubiquitin-like modifier modulates abscisic acid signaling in Arabidopsis. Plant Cell. 2003;15:1347-59.

62. Miura K, Nozawa R. Overexpression of SIZ1 enhances tolerance to cold and salt stresses and attenuates response to abscisic acid in Arabidopsis thaliana. Plant Biotechnol J. 2014;31:167-72.

63. Miura K, Ohta M. SIZ1, a small ubiquitin-related modifier ligase, controls cold signaling through regulation of salicylic acid accumulation. J Plant Physiol. 2010;167:555-60.

64. Li Z, Hu Q, Zhou M, Vandenbrink J, Li D, Menchyk N, et al. Heterologous expression of OsSIZ1, a rice SUMO E3 ligase, enhances broad abiotic stress tolerance in transgenic creeping bentgrass. Plant Biotechnol J. 2013;11:432-45.

65. Miller MJ, Barrett-Wilt GA, Hua Z, Vierstra RD. Proteomic analyses identify a diverse array of nuclear processes affected by small ubiquitin-like modifier conjugation in Arabidopsis. Proc Natl Acad Sci U S A. 2010;107:16512-7.

66. Miller MJ, Vierstra RD. Mass spectrometric identification of SUMO substrates provides insights into heat stress-induced SUMOylation in plants. Plant Signal Behav. 2011;6:130-3.

67. Miller MJ, Scalf M, Rytz TC, Hubler SL, Smith LM, Vierstra RD. Quantitative proteomics reveals factors regulating RNA biology as dynamic targets of stress-induced SUMOylation in Arabidopsis. Mol Cell Proteomics. 2013;12:449-63.

68. Zheng Y, Schumaker KS, Guo Y. Sumoylation of transcription factor MYB30 by the small ubiquitin-like modifier E3 ligase SIZ1 mediates abscisic acid response in Arabidopsis thaliana. Proc Natl Acad Sci U S A. 2012;109:12822-7.

69. Son GH, Park BS, Song JT, Seo HS. FLC-mediated flowering repression is positively regulated by sumoylation. J Exp Bot. 2014;65:339-51.

70. Lavarack B, Harris W, Stocker G. Dendrobium and its relatives. Portland, Ore, USA: Timber Press; 2000.

71. Yu H, Goh CJ. Molecular genetics of reproductive biology in Orchids. Plant Physiol. 2001;127:1390-3.

72. Srikanth A, Schmid M. Regulation of flowering time: all roads lead to Rome. Cell Mol Life Sci. 2011;68:2013-37.

73. Jin JB, Hasegawa PM. Flowering time regulation by the SUMO E3 ligase SIZ1. Plant Signal Behav. 2008;3:891-2.
74. Song J, Angel A, Howard M, Dean C. Vernalization - a cold-induced epigenetic switch. J Cell Sci. 2012;125:3723-31.

75. Gillespie RJ. The Orchids, a scientific survey. The New York Botanical Garden. 1959;13:371

76. Clough SJ, Bent AF. Floral dip: a simplified method for Agrobacteriummediated transformation of Arabidopsis thaliana. Plant J. 1998;16:735-43.

77. Budhiraja R, Hermkes R, Müller S, Schmidt J, Colby T, Panigrahi K, et al. Substrates related to chromatin and to RNA-dependent processes are modified by Arabidopsis SUMO isoforms that differ in a conserved residue with influence on desumoylation. Plant Physiol. 2009;149:1529-40.

78. Fu S, Lin C, Kao T, Huang D, Huang H. PaPTP1, a gene encoding protein tyrosine phosphatase from Orchid, Phalaenopsis amabilis, is regulated during floral development and induced by wounding. Plant Mol Biol Rep. 2011;29:106-16.

79. Li G, Liu K, Baldwin SA, Wang D. Equilibrative nucleoside transporters of Arabidopsis thaliana CDNA cloning, expression pattern, and analysis of transport activities. J Biol Chem. 2003;278:35732-42.

80. Fu X, Deng S, Su G, Zeng Q, Shi S. Isolating high-quality RNA from mangroves without liquid nitrogen. Plant Mol Biol Rep. 2004;22:197.

81. Larkin MA, Blackshields G, Brown NP, Chenna R, McGettigan PA, McWilliam $H$, et al. Clustal W and Clustal X version 2.0. Bioinformatics. 2007:23:2947-8.

82. Hasegawa M, Kishino H, Saitou N. On the Maximum Likelihood method in molecular phylogenetics. J Mol Evol. 1991;32:443-5.

83. Kumar S, Nei M, Dudley J, Tamura K. MEGA: a biologist-centric software for evolutionary analysis of DNA and protein sequences. Brief Bioinform. 2008;9:299-306.

\section{Submit your next manuscript to BioMed Central and take full advantage of:}

- Convenient online submission

- Thorough peer review

- No space constraints or color figure charges

- Immediate publication on acceptance

- Inclusion in PubMed, CAS, Scopus and Google Scholar

- Research which is freely available for redistribution 